\title{
Colorectal cancer treatment using bacteria: focus on molecular mechanisms
}

\author{
Sara Ebrahimzadeh ${ }^{1 \dagger}$, Hossein Ahangari ${ }^{2 \dagger}$, Alireza Soleimanian ${ }^{3}$, Kamran Hosseini $^{4}$, Vida Ebrahimi ${ }^{5}$, \\ Tohid Ghasemnejad ${ }^{4}$, Saiedeh Razi Soofiyani ${ }^{6}$, Vahideh Tarhriz ${ }^{4^{*}}$ (D) and Shirin Eyvazi ${ }^{7,8^{*}}$
}

\begin{abstract}
Background: Colorectal cancer which is related to genetic and environmental risk factors, is among the most prevalent life-threatening cancers. Although several pathogenic bacteria are associated with colorectal cancer etiology, some others are considered as highly selective therapeutic agents in colorectal cancer. Nowadays, researchers are concentrating on bacteriotherapy as a novel effective therapeutic method with fewer or no side effects to pay the way of cancer therapy. The introduction of advanced and successful strategies in bacterial colorectal cancer therapy could be useful to identify new promising treatment strategies for colorectal cancer patients.
\end{abstract}

Main text: In this article, we scrutinized the beneficial effects of bacterial therapy in colorectal cancer amelioration focusing on different strategies to use a complete bacterial cell or bacterial-related biotherapeutics including toxins, bacteriocins, and other bacterial peptides and proteins. In addition, the utilization of bacteria as carriers for gene delivery or other known active ingredients in colorectal cancer therapy are reviewed and ultimately, the molecular mechanisms targeted by the bacterial treatment in the colorectal cancer tumors are detailed.

Conclusions: Application of the bacterial instrument in cancer treatment is on its way through becoming a promising method of colorectal cancer targeted therapy with numerous successful studies and may someday be a practical strategy for cancer treatment, particularly colorectal cancer.

Keywords: Colorectal cancer, Biotherapeutical toxins, Bacteriocins, Bacterial peptides

\section{Introduction}

Colorectal cancer (CRC) is a serious disease characterized as uncontrolled division or abnormal growth of colon or rectum cells. CRC is the second major cause of cancer-related global mortality [1]. In the United States, almost close to 150,000 new cases of CRC are identified per annum. However, the greatest prevalence has been reported from Australia, New Zealand, Europe, and North America, while the lowest rates have been

\footnotetext{
* Correspondence: t.tarhriz@yahoo.com; Shirin_Biotech@yahoo.com

† Sara Ebrahimzadeh and Hossein Ahangari contributed equally to this work.

${ }^{4}$ Molecular Medicine Research Center, Biomedicine Institute, Tabriz University of Medical Sciences, Tabriz, Iran

${ }^{7}$ Department of Biology, Tabriz Branch, Islamic Azad University, Tabriz, Iran

Full list of author information is available at the end of the article
}

reported from Africa and South-Central Asia [2]. The risk of developing CRC is affected by genetic, epigenetic and environmental factors [3]. Genetic risk factors such as Type 2 diabetes, family history of CRC, and history of inflammatory bowel disease (IBD) can increase the risk of CRC in a long period. The utilization of antiinflammatory medications for the treatment of IBD considerably reduces the risk of $\mathrm{CRC}$ incidence [4, 5]. Nevertheless, the great portion of CRC cases has been associated with environmental factor such as a sedentary lifestyle, unhealthy diet, smoking, and obesity. Besides the aforementioned risk factors, the pathogenic microorganisms can also play a critical role to develop CRC [6]. The large intestine is an organ continuously exposed to bacteria like Fusobacterium sp., Porphyromonas,

(c) The Author(s). 2021 Open Access This article is licensed under a Creative Commons Attribution 4.0 International License, which permits use, sharing, adaptation, distribution and reproduction in any medium or format, as long as you give appropriate credit to the original author(s) and the source, provide a link to the Creative Commons licence, and indicate if changes were made. The images or other third party material in this article are included in the article's Creative Commons licence, unless indicated otherwise in a credit line to the material. If material is not included in the article's Creative Commons licence and your intended use is not permitted by statutory regulation or exceeds the permitted use, you will need to obtain permission directly from the copyright holder. To view a copy of this licence, visit http://creativecommons.org/licenses/by/4.0/ The Creative Commons Public Domain Dedication waiver (http://creativecommons.org/publicdomain/zero/1.0/) applies to the data made available in this article, unless otherwise stated in a credit line to the data. 
Escherichia coli, Helicobacter pylori, Citrobacter rodentium, Bacteroidetes, and Prevotella, which are all reported prevalently in the biopsies of patients with CRC [7-10].

There are several conventional CRC treatment strategies starting from simple endoscopic polypectomy to wider surgical, to radio-chemotherapy combinations and end in complicated chemotherapeutical regimens mixed with drugs. However, these treatment strategies all have their own drawbacks and side effects [11]. Studies for finding highly selective treatments have indicated that although bacteria account for a large number of cancers, most of them have antimicrobial and antifungal activities, which can be used in cancer therapy [12-14]. William B. Coley who used combination of Serratia marcescens initially presented cancer therapy using bacteria in the late nineteenth century and Streptococcus pyogenes to treat sarcomas, witnessed tumor abatement, and increased patient survival. After his novel discovery, numerous studies have shown phenomenal results in using various bacteria in the eradication of different tumors. In the current study, the recent advances in CRC therapy utilizing bacteria are presented and focused on the molecular mechanisms that are targeted by the bacterial treatment in the CRC tumors. Introduction of advanced and successful strategies in bacterial CRC therapy could be useful to identify novel promising treatment strategies for CRC patients.

\section{Bacterial cancer therapy}

Cancer is a serious debilitating cause of death in recent decades that has enforced scientists to discover new prevention and treatment methods. Among the methods, bacterial therapy is one of the attractive strategies. Although good results were obtained from these treatments, conversely there were qualms due to the bacterial infections [15]. A safe bacterium-mediated cancer therapy should have features such as cancer cytotoxicity or immunogenicity, reducing toxicity to intact cells, cancer selectivity as well as stability in the human body conditions. The secretion of cancer cytotoxic substances by the different bacterial strains has been widely reported, whereas so far, the knowledge about responsible genes of these secreting substances is challenging [10]. According to the confirmation of the safety of bacterial cancer therapy, researchers have used Clostridia and Streptococci species for this purpose in the previous research, but nowadays, the main focus is on the genetically modified species owing to their greater capability of binding to cancer cells $[16,17]$. Bifidobacteria sp., Salmonellae sp. and Clostridia sp. are the common species that have been tested in animal models bearing various tumors. The bacteria act as a vector for the delivery a wide range of genes such as anti-angiogenic genes, apoptosis genes, tumor suppressor genes, and tumor-linked antigens $[18,19]$. Genetically modified bacteria can be expended in the acceleration of cancer detection as dual diagnostic and medicinal instruments. In this regard, a large number of studies have discovered that genetically modified bacteria can have a more significant multiplication in tumors than in normal tissues [20]. Cytotoxicity of bacteria in various tumor cells and their secreted substances are listed in Table 1.

\section{Colorectal cancer therapy using bacteria}

Using bacteria for the treatment of CRC has become an important issue for many researchers and various mechanisms have been recognized for bacteria's role in CRC treatment (Fig. 1). Toxins secreted from bacterial are the other effective therapeutic agents that have been utilized for CRC therapy. It has been shown that bacterial peptides are the potent agents in CRC therapy. In addition, secreted substances from bacteria which are used as a carrier and combining them with medications to targeted delivery of some anticancer medications to cancerous cells is another method using bacteria in CRC treatment [10]. For example, in recent published

Table 1 Bacterial strains with cancer cytotoxic traits

\begin{tabular}{|c|c|c|c|}
\hline Bacteria & Substance & Cancer type & Reference \\
\hline Streptomyces fradiae & L-asparaginases & $\begin{array}{l}\text { Colorectal } \\
\text { Adenocarcinoma }\end{array}$ & {$[21]$} \\
\hline Brevibacillus spp. & Laterosporulin 10 & $\begin{array}{l}\text { Breast cancer, embryonic } \\
\text { kidney cancer }\end{array}$ & [22] \\
\hline Streptomyces albulus & L-lysin $(\varepsilon-P L)$ & Hepatocellular carcinoma & [23] \\
\hline Enterobacter cloacae & L-asparaginases & Leukemia & [24] \\
\hline Corynebacterium Diphtheriae & Diphtheria toxin & $\begin{array}{l}\text { Adrenocortical } \\
\text { carcinoma, cutaneous T cell lymphomas }\end{array}$ & [25] \\
\hline Pseudomonas aeruginosa, Sphingobacterium spp. & Arginine deiminase & Prostate carcinoma, colon adenocarcinoma & {$[26]$} \\
\hline Serratia surfactantfaciens & Serrawettin W2 & Cervical carcinoma & {$[27]$} \\
\hline Clostridium novyi & Phospholipases & Colon carcinomas, sarcoma & {$[28]$} \\
\hline
\end{tabular}




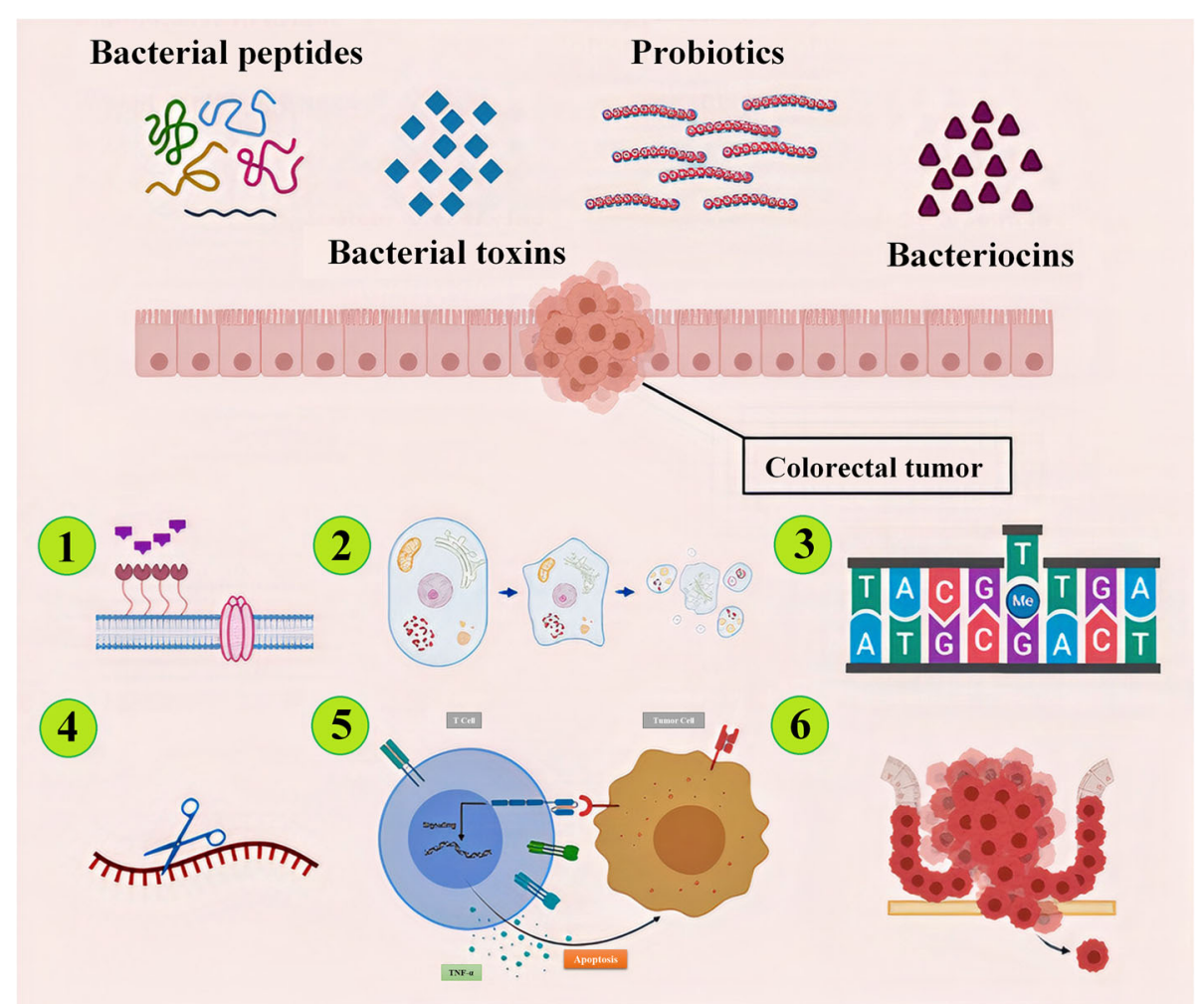

Fig. 1 The colorectal cancer bacterial therapy can be performed by means of bacterial whole cell such as probiotics or bacterial-associated peptides like bacteriocins or bacterial toxins. The anticancer effect of this treatment can be achieved by different mechanisms: 1) Pore forming in the cell membrane 2) Induction of apoptosis 3) DNA alkylation 4) RNase activity 5) TNF-a production 6) Inhibition of metastasis [10, 29]

research, 5-Fluorouracil (5-FU) resistant CRC cells have shown that they are responsive to the combination of 5FU and Lactobacillus plantarum; consequently, the combination resulted in further anti-cancer activity for cells. However, the role of bacteria in the administration of probiotics as a complementary treatment to combat CRC should not be overlooked [29].

\section{Bacteriocins for CRC therapy}

Bacteriocins are antibacterial peptides synthesized by many bacteria's ribosomes to inhibit the growth of other bacterial strains. Some of these bacteriocins are reported with anti-cancer features [30]. Several bacteriocins that have reported efficacious tumoricidal activity on CRC are nisin, colicin, microcin and pediocin. Nisin is a positive charged molecule that causes pore development in the cell membrane of the target organism and thereby results in cytoplasmic membrane depolarization [31]. Nisin is synthesized and secreted by Lactococcus lactis appeared to have a considerable cytotoxic effect against CRC cell lines such as Caco-2 and HT-29 colorectal cancer cell lines [32]. In a study that the apoptotic effect of nisin on the SW480 cells was investigated, cell viability and $\mathrm{Bax} / \mathrm{Bcl}-2$ ratio at both mRNA and protein levels were considered. It has been shown that the doses of
$2000-4000 \mu \mathrm{g} / \mathrm{ml}$ of nisin had a significant antiproliferative impact on SW480 cell line and also could increase the apoptotic index $(p<0.05)$ [33]. Apart from anti-proliferative feature of nisin, it is known to have a potential preventing effect against the expression of metastatic genes such as MMP2, MMP9, cytolethal distending toxins (CDTs) and the cycle inhibiting factor (Cif), and up-regulates the expression of the genes inhibitors in CRC cell lines such as LS-180, HT-29, SW480, and Caco-2 [34].

Data showed that the expression level of carcinoembryonic antigen (CEA) is associated with metastasis of CRC cells. Norouzi et al., (2018) showed that nisin decreased the CEA level in condition media of colorectal cancer cell lines [34]. One of the mentioned roles of nisin is the enhancing the cytotoxicity of some chemotherapeutics when used as a combination. Furthermore, nisin was shown to be a cytotoxic agent that acts as a cell membrane disrupter and an apoptotic pathway activator. This function can be represented alone or in combination with chemotherapeutic agents such as Etoposide, 5-FU, and Hydroxyurea. It has been reported that the combination of nisin with conventional therapies lowered the therapeutic doses of these anti-cancer drugs [35]. Colicin is another bacteriocin released from 
Enterobacteriaceae (e.g., E. coli) that inhibits the growth of other bacteria and lessens the competition. Available evidence shows that the cytotoxic effect of different colicins on various cancerous cells are likely through poreforming, a non-specified DNase activity, RNase activity, and inhibitory effect on murein biosynthesis [36]. In this way, the cytotoxic effect of different colicins has been studied in vitro on HT-29 cell lines (a type of human colon cancer cell line) [37]. Going into depth, in this study, the growth inhibitory effect of colicins E1, E3, A, and $U$ on 11 human cancer cell lines, in addition to HT29, was explored. Results revealed that HT-29 colon carcinoma cells are insensitive in response to colicin E1 and the highest cytotoxicity against HT-29 was achieved by colicin A treatment [37]. However, it was not mentioned that Colicin has more toxicity to tumor cells in comparison to the normal cells [38]. For instance, microcin E492 is a part of Klebsiella Pneumoniae. colicins have a cytotoxic effect against colorectal carcinoma cells while there is not any reaction against the normal cells [10]. Besides, comparing the anti-tumorigenic effect of microcin E492 on two different cell lines (HT-29 and SW620) in both in vitro and in vivo showed that microcin E492 has more cytotoxicity effect on the HT-29 cell line compared with SW620. The impact is believed to happen by the mechanism of apoptosis. For in vivo investigation, SW620 zebrafish larvae xenografts were developed. The intratumoral injection of microcin E492 reduced tumor growth significantly [32]. Studies indicated microcin depolarizes cell membrane potential by pore-forming ability, and also DNA fragmentation, phosphatidylserine release, caspase activity, and releasing of intracellular calcium ions are the principle mechanisms of apoptotic cell death by inducing microcin [39]. Pediocin is another bacteriocin that has cytotoxic effects on CRC cells such as HT-29 and DLD-1. The toxin is secreted by Pediococcus acidilactici (K2a2-3) which is isolated from the intestine of Philippine water buffalo [40]. The different important bacteriocins, which can be used in CRC therapy, are summarized in Table 2.

\section{Bacterial toxins in CRC therapy}

Toxins and other bacterial components have been studied since they have a crucial role as anti-cancer substances. Numerous investigated evidence show that bacterial toxins act as a valuable inhibitor of cancerous cell growth. Bacterial toxins have a twofold manner on cancer cells based on the concentration. In other words, they can cause cell death or amplify the cell's proliferation. To shed more light on this issue, in high levels, they can lyse these cells whereas in low concentrations they can modify the cellular procedures which are responsible for proliferation and apoptosis regulation [42]. Two different anti-cancer toxins have been recognized in bacteria which include toxins with the ability to conjugate on surface antigens of cancerous cells and toxins which can conjugate the ligands of cancer cells. Cyclomodulins refer to bacterial toxins that stimulate or block the eukaryotic cell cycle. In addition, cytotoxic necrotizing factor (CNF) is another toxin released by certain bacterial strains like E. coli $\mathrm{K}-12$. CNF motivates the transition of G1-S cycle as well as DNA duplication, which causes the cells to become multinucleated without any changes in the total number of cells. This is probably due to the toxin capability preventing cell differentiation and activating cell apoptosis [43].

Generally, CRC cells have numerous tumor-specific antigens on their surface and most of them act as receptors. Several toxins like diphtheria toxin (DT) become activated after binding to these receptors [44]. The toxins can act as a ligand for binding to selective receptors on the target cell [45]. We briefly described some bacterial toxins that have been used in CRC therapy studies. One of the successful toxins in CRC therapy is enterotoxin (CPE) produced by $C$. perfringens. It has been shown that CPE exactly attaches to claudin-3 and claudin- 4 which abundantly exist on the cancerous cell surface. This complex is known as a "multi-protein membrane pore complex" and causes the lysis of cancerous cells through losing cellular osmotic equilibrium. The anti-cancer feature of CEP for CRC cells was confirmed in in vivo and in vitro studies [46, 47]. For instance, Pahle et al., (2017) verified an optimized CPE expressing vector as a target for claudin-3 and/or claudin-4 expressing in colon cancer cells including SW480, HCT-116, SW620, Caco-2, HT-29 and PDX (patient-derived colon carcinoma xenografts). The results showed that the CPE is a gene transfer system and can be considered as an appealing therapeutic agent in colon carcinomas through the targeting of claudin-3

Table 2 Bacteriocins in colorectal cancer therapy

\begin{tabular}{llllll}
\hline Bacteriocin & Producer microorganism & Molecular weight (kda) & Affected Cell lines & Reference \\
\hline Nicin & Lactococcus lactis & 3.5 & Caco-2, HT-29, LS-180, SW48 & [41] \\
Colicin & $\begin{array}{l}\text { Enterobacteriaceae } \\
\text { (e.g. E. coli) }\end{array}$ & 4.1 & HT-29 & \\
Microcin E492 & Klebsiella pneumoniae & 7.8 & CRC cells, HT-29, SW620 & [36] \\
Pediocin & Pediococcus acidilactici K2a2-3 & 6 & HT-29, DLD-1 & [32] & [40] \\
\hline
\end{tabular}


and/or claudin-4 which lead to rapid and impressive tumor cell killing in both in vitro and in vivo conditions [46]. On the molecular scale, the transfection of optCPE directs rapid cytotoxic effects including necrosis in claudin expressing cells due to the membrane breakdown. On the other hand, massive necrosis and decrease in tumor cell growth in colon carcinoma PDX bearing mice were detected because of the intratumoral optCPE expression. Therefore, it was revealed that optCPE gene transfer causes lysis in claudin-positive tumor cells, while claudin-negative cells stayed unchanged. Szeponik et al., demonstrated that DT effect on regulatory T cells $\left(\mathrm{T}_{\mathrm{reg}}\right)$ depletion and its effect on the density as well as of on and effector action of various $\mathrm{TCR}^{\alpha \beta+}$ and $\mathrm{TCR}^{\gamma \delta+} \mathrm{T}$ cell populations in intestinal tumors. In this study, the $\mathrm{APC}^{\mathrm{Min} /{ }^{+}} \backslash$ DEREG mouse model has used which ports a DT receptor under the control of the FOXP3 promoter to deplete $\mathrm{T}_{\text {reg }}$ in mice suffering CRC. They have indicated that the density of conventional $\mathrm{TCR}^{\alpha \beta+} \mathrm{CD}^{\alpha \beta+} \mathrm{T}$ cells was meaningfully increased in $\mathrm{T}_{\text {reg }}$ depleted tumors and $\mathrm{T}$ cells showed improved activation and proliferation in addition to increased IFN- $\gamma$ and Granzyme B production. Investigating the molecular mechanisms via immunohistochemistry staining and flow cytometry demonstrated a noteworthy proliferation of $\mathrm{CD} 8 \alpha \beta \mathrm{T}$

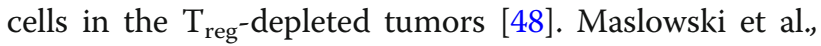
(2019) depleted a Salmonella enterica serovar Typhimurium (STm) in mice CRC cells for evaluation of the mechanisms and efficiency of medication they employed an Aromatase A-deficient STm $\left(\mathrm{STm}^{\Delta \mathrm{aroA}}\right)$. STm ${ }^{\Delta \text { aroA }}$ which was delivered by oral gavage showed that it has the ability to meaningfully decrease the tumor load in intestinal cancer models, $\mathrm{Apc}^{\mathrm{min} /+}$ mice. The colonization of $\mathrm{STm}^{\Delta \mathrm{aroA}}$ in tumor cells causes the modification in the mRNA transcription which correlated with the epithelial-mesenchymal transition, cell cycle-related transcripts and metabolic. The analysis of metabolomics in tumor cells confirmed the changes in the metabolic condition of $\mathrm{STm}^{\Delta \mathrm{aroA}}$ treated tumors, revealing that $\mathrm{STm}^{\Delta \text { aroA }}$ inflicts some metabolic antagonism on the tumor cells. In conclusion, the $\mathrm{STm}^{\mathrm{AaroA}}$ in in vitro tumor organoid condition has direct effect on tumor epithelium and results to change in transcripts and metabolites which is similar to what happens in vivo-treated tumors [49].

\section{Bacterial peptides in CRC therapy}

Using biomaterial is another effective agent in cancer therapy, which has a profound effect on tumor cells as an anti-proliferative agent. Because they can activate lymphocytes and macrophages as well as induce the production of tumor necrosis factor $\alpha$ (TNF- $\alpha$ ) as a cytotoxic substance, are activated by microbial infections [50]. These types of peptides are characterized by hydrophobicity and low molecular weight (in the range of 3 $\mathrm{kDa}$ to $10 \mathrm{kDa}$ ) that are very vital for their penetration into the cancer cells to inhibit their growth. Several types of bacterial peptides were demonstrated that can arrest cell cycle progresses while some of them can induce apoptosis. Furthermore, some types of bacterial peptides are better than chemotherapy drugs due to the fact that using bacterial peptides reduce side effects or even don't have any side effect. To name but few some of these kinds of peptides such as azurin, pediocin K2a2-3, mitomycin C, Enterococcal anti-proliferative peptide (Entap), and Nonribosomal Peptides (NRPs) can be used by clinicians in the cancer treatment process (Table 3).

\section{Azurin}

Azurin is a kind of copper containing protein secreted by $P$. aeruginosa. The protein has anti-cancer activity when present in blood $[58,59]$. The anti-cancer activity is related to several mechanisms such as forming complexes with p53 tumor suppressor, interferential activity on the receptor of tyrosine kinase EphB2-mediated signaling process, reducing of activity of VEGFR-2 tyrosine kinase, preventing of angiogenesis, and interferential activity on P-cadherin protein expression [25]. Azurin operates as an electron transfer shuttle in bacterial species. According to

Table 3 Some of the important bacterial peptides that have been used for CRC therapy

\begin{tabular}{lll}
\hline Peptide/Protein & Source & References \\
\hline Azurin & Pseudomonas aeruginosa & {$[25,51,52]$} \\
Pediocin K2a2-3 & Pediococcus acidilactici K2a2-3 & {$[40]$} \\
Mitomycin C & Streptomyces caespitosus & {$[10]$} \\
Entap & Enterococcus sp. & {$[32]$} \\
Lucentamycin A and B & Nocardiopsis lucentensis CNR-712 & {$[53]$} \\
Arenamide A and B & Salinispora arenicola & {$[54]$} \\
Ohmyungsamycins & Streptomyces sp. & {$[55]$} \\
Mixirins & Bacillus sp. & {$[56]$} \\
Urukthapelstatin A & Mechercharimyces asporophorigenens YM11-542 & {$[57]$} \\
\hline
\end{tabular}


mentioned azurin anti-cancer mechanisms, complex forming between p53 and azurin can help p53 to be stable and improve its function by inhibiting COP1-mediated ubiquitination, and causes proteasome degradation, therefore p53 induces cell cycle arrest at G2/M and this inhibits the cancer development. Some kinds of biological assays such as apoptosis assay (by using flow cytometry) and cytotoxicity assay (like MTT assay) approve these functions [51]. Other cancer cell lines that azurin can exert its cytotoxic role on them are oral squamous carcinoma (YD9), breast cancer (MCF-7, MDA-MB-157), and melanoma (UISO-Mel-2) [60].

\section{Pediocin K2a2-3}

Pediocin K2a2-3 was first isolated from Pediococcus acidilactici K2a2-3 and has shown an effective anticancer role [31, 61, 62]. Reference to previous research [40], pediocin K2a2-3 found to be cytotoxic against HT29 colon adenocarcinoma cells because of hydrophobicity of this peptide based on MTT assay. The hydrophobic nature of this peptide may be the reason for its cytotoxicity. This high hydrophobicity pediocin was an advantage for the first step purification process of it from the supernatant of strain overnight culture. After partial purification, the $\mathrm{pH}$-mediated method was utilized to obtain dialyzed and undialyzed extracts [40].

\section{Mitomycin C}

Mitomycin $\mathrm{C}$ is a kind of antibiotic that is used as anticancer material and was isolated from Streptomyces caespitosus. The molecular weight and molecular formula of mitomycin $\mathrm{C}$ are $334 \mathrm{Da}$ and $\mathrm{C}_{15} \mathrm{H}_{18} \mathrm{~N}_{4} \mathrm{O}_{5}$. This antibiotic is used in the treatment of some cancers such as colorectal, anal carcinomas, lungs, head, neck, and breast cancer. This kind of anti-tumor antibiotic binds to DNA on the alkylation and inhibits DNA synthesis [10]. An enzymatic bio-reduction requires for the reduction of mitomycin $\mathrm{C}$ and its activation. After reduction, a very reactive bis-electrophilic is formed that alkylates cellular nucleophiles which is the main mechanism of mitomycin C. Moreover, the cytotoxic effects of mitomycin $\mathrm{C}$ is related to the formation of DNA-DNA interactions [10]. Therefore, it has a very critical role in the treatment of cancers.

\section{Enterococcal anti-proliferative peptide (Entap)}

Another type of bacterial peptide that has antiproliferative activity is Entap. This type of peptide produced by Enterococcus sp. and arrest cancer cells in G1 and stimulation of autophagic apoptosis. Cancer cell studies demonstrated numerous vacuoles and autolysosomes and autophagosomes structures in the cells. Entap has anti-proliferative activity against prostatic carcinoma (22Rv1), mammary gland adenocarcinoma (MDA-MB-
231), human gastric adenocarcinoma (AGS), uterine cervix adenocarcinoma $(\mathrm{HeLa})$, and colorectal adenocarcinoma (HT-29) cell lines [32].

\section{Nonribosomal peptides (NRPs)}

Bacteria, fungi, and cyanobacteria can synthesize Nonribosomal peptides (NRPs) and bioactive metabolites which have anti-cancer activity [63]. Some of NRPs have an anti-colorectal activity, which include lucentamycins, arenamides, ohmyungsamycins, mixirins, and urukthapelstatin A.

\section{Lucentamycins}

Lucentamycins (A-D), 3-methyl-4-ethylideneprolinecontaining peptides are type of cytotoxic peptides isolating from the crude extract of Nocardiopsis lucentensis CNR-712. Four structurally different lucentamycins (Fig. 2) were isolated by culture extract fractionation. After the structure determination of each compound by NMR technique, the bioassay test (3-(4,5-dimethylthiazol-2-yl)-5-(3-carboxymethoxyphenyl)-2-(4-sulfophenyl)-2H-tetrazolium (MTS) assay) was performed to measure cytotoxic activity against HCT-116 colon carcinoma cell line. The in vitro cytotoxicity of lucentamycins A and B was significant with the IC50 of $0.2 \mu \mathrm{M}$ and $11 \mu \mathrm{M}$ [53].

\section{Arenamides}

Salinispora arenicola secreted new types of cyclohexadepsipeptides (arenamides A to C) in sea sediment. Previous research have shown that TNF-induced activation is blocked by arenamides A and B. These kind of arenamides have important roles in inhibition of nitric oxide and prostaglandin E2 production and also moderate cytotoxic effect on human colon carcinoma (HCT-116) [54].

\section{Ohmyungsamycins}

Cyclic peptides ohmyungsamycin A and B were secreted by Streptomyces sp. which both of them are comprise of amino acid units, such as N,N-dimethylvaline, $\beta$ hydroxyphenylalanine, and N-methyl-4-methoxytrytophan. Growth inhibition and anti-proliferative activity against various cancerous cell lines were demonstrated by ohmyungsamycin A and B [55].

\section{Mixirins}

Three kinds of cyclic acylpeptides (mixirins A to C) are secreted by the marine bacterium Bacillus sp. Their formula are $\mathrm{C}_{48} \mathrm{H}_{75} \mathrm{~N}_{12} \mathrm{O}_{14}, \quad \mathrm{C}_{45} \mathrm{H}_{69} \mathrm{~N}_{12} \mathrm{O}_{14}$ and $\mathrm{C}_{47} \mathrm{H}_{73} \mathrm{~N}_{12} \mathrm{O}_{14}$, respectively, and the molecular weight of them are about $1 \mathrm{KDa}$. All of the mixirins (A, B, and $\mathrm{C}$ ) can block the growth of HCT-116 (human colon tumor cell line) [56]. 


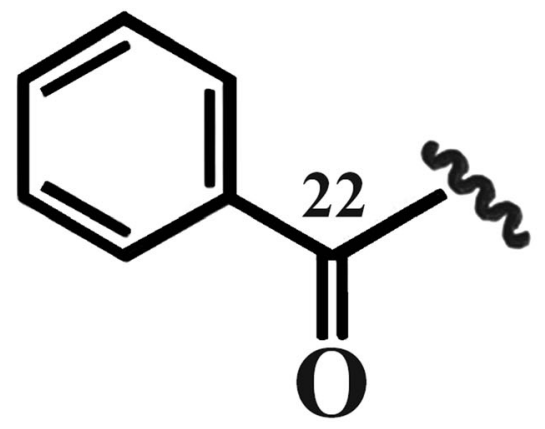

Lucentamycin A

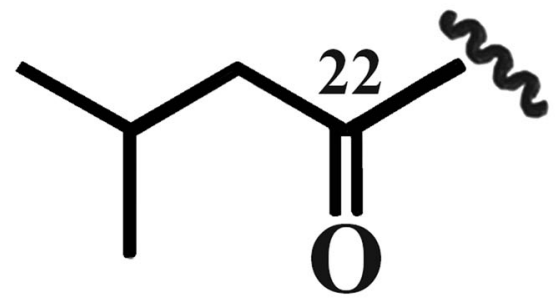

Lucentamycin C

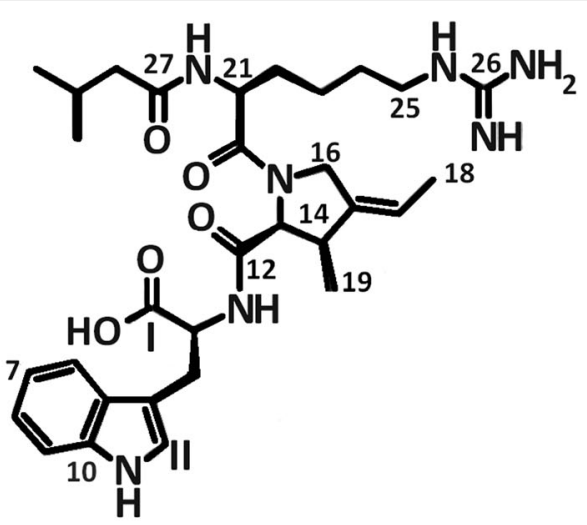

Lucentamycin B

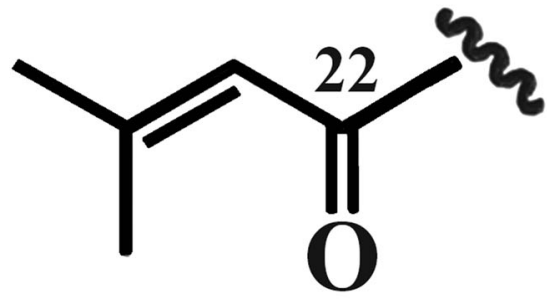

Lucentamycin D

Fig. 2 Four different structure of Lucentamycins including Lucentamycins A, B, C and D [53]

\section{Urukthapelstatin a}

A cyclic thiopeptide-urukthapelstatin A is secreted by Mechercharimyces asporophorigenens YM11-542. The molecular formula and weight of urukthapelstatin are $\mathrm{C}_{34} \mathrm{H}_{30} \mathrm{~N}_{8} \mathrm{O}_{6} \mathrm{~S}_{2}$ and $733 \mathrm{Da}$, respectively. Some previous research have shown the anti-cancer roles of urukthapelstatin A by growth inhibition against breast cancer (MCF7), lung cancer (A549, NCI-H460, and DMS-114), ovarian cancer (SK-OV3, OVCAR-8, OVCAR-5, OVCAR-4, and OVCAR-3) and colon cancer (HCT-116) [57].

\section{Bacteria as carriers for colorectal cancer therapeutic agents}

While traditional cancer therapeutics are not capable of eliminating completely cancerous cells in anaerobic regions, bacteria as targeted delivery vectors are promising tools to carry anti-cancer genes or anti-tumor medications to hypoxic areas in tumors [64]. Since tumors are in hypoxic regions, anaerobic bacteria can present in the tumor environments [65]. Bacteria have specific metabolic characteristics that enable them to invade tumor cells as a feature that can't be reached by conventional all therapeutic agents [10]. For instance, some strains can release secondary bioactive metabolites that are synthesized by a complex of the enzyme called non- ribosomal peptide synthetases (NRPSs). These peptides have specific characteristics in their structures including $\mathrm{N}$-terminally attached fatty acid chains, D-amino acids, $\mathrm{N}$ - and C-methylated residues, glycosylated amino acids and heterocyclic elements, as well as phosphorylated residues. Hence, using these biological gene vectors results in a minimized dose and reduced toxicity [66]. Here, some of the examples of bacteria that are utilized as a vector for the treatment of colorectal cancer are discussed. These bacteria can cross the intestinal mucosa and trigger systemic immunity and mucosal immunity. Therefore, virulence-attenuated bacteria are appropriate carriers for heterologous protein delivery, DNA vaccines and other molecules for vaccination or treatment goals due to the specific metabolic characteristics [67]. For instance, Lysteria monocytogenes as an intracellular microorganism has been utilized as a vector for anti-cancer vaccines. It passes from intestinal membranes and activates immune responses. For example, it triggers CD8 and CD4 T-cells activity against tumors. It has also been found to be safe in clinical trials [68]. A recent study indicated that using a model of hepatic metastasis of colorectal cancer, demonstrated that making use of $L$. monocytogenes as a vector for a cancer vaccine notably magnifies the anti-tumor activity [69]. Salmonella 
typhimurium is another promising bacterium used for the delivery of anti-cancer agents. It is compatible with both aerobic and anaerobic environments, so it homes in both large and small tumors and activities innate or acquired immune response against tumors by activating of Toll-Like receptors (TLR) signaling pathway. TLR recognize the conserved component of Salmonella typhimurium which known as PAMPs (pathogen-associated molecular patterns) [70, 71]. In addition, administration of S. typhimurium systematically induces inflammasome pathways as bacteria colonize in the tumor area. The inflammasomes activate caspase- 1 which cleavage proIL-1 $\beta$ and pro-IL-18 to produce active IL- $1 \beta$ and IL-18. On the whole, systemic administration of the bacteria induces pro-inflammatory cytokines production and activates the immune cells in the tumor site. S. typhimurium is a commonly used vaccine vector. Vector for 4$1 \mathrm{BB}$ ligand (4-1BBL) which is a DNA-based vaccine that successfully suppresses colorectal cancer progress in rats by triggering $\mathrm{T}$ cell-mediated immunity. Another example is E. coli Nissle 1917, an intestinal probiotic which has been used as a vector to deliver p53 and Tum- 5 protein to tumor regions [64]. Engineered EcN is utilized to carry a genomic luxCDABE cassette holding a highly expressed lacZ vector in a murine model of colorectal cancer. EcN quickly localized in the gastrointestinal tract and colonized within the metastatic tumors, not in healthy organs [72]. Finally, Clostridium novyi-NT is a liposomal drug deliverer such as Doxorubicin to colon tumor cells [73] (Table 4). The potential of C. novyi-NT to modulate the tumorous area leads it to be a promising carrier for chemotherapeutic agents that target colorectal cancer cells. Several examinations illustrated that some therapeutic agents can decrease immune suppression, which is caused by tumors. For example, Doxorubicin, anti-metabolites gemcitabine and 5-FU can decrease the number of MDSCs. therefore, they can diminish immune suppression. Thereupon, delivering 5-FU with C. novyi-NT seems to be a rational and highly effective method to combat CRC cells [77, 78]. Some of the molecular mechanisms in bacterial therapy are shown in Fig. 3 .

\section{Limitations of bacteriotherapy methods}

As previously discussed, bacteriotherapy involves the use of bacteria or their products to treat diseases and generally involves the use of probiotics, fecal matter transplantation (FMT) or intestinal microbiota transplantation (IMT), and synbiotics [79], and each in turn, has advantages and disadvantages that have attracted the attention of researchers. For example, in the FMT method in which a healthy person's liquid stool suspension is injected into a patient, are some limitations that include the cost of the technique, the availability of stool donors, and the time of screening. Therefore, researchers have been able to overcome this limitation in the treatment of colorectal cancer by using frozen feces [80-82]. Numerous studies have shown that the combination of bacteriotherapy methods with different therapeutic approaches in the treatment of various cancers, especially colorectal cancer, has limitations. In this regard, researchers have mentioned limitations in combining chemotherapy and bacteriotherapy methods, such as incorrect targeting of the tumor, lack of proper penetration into the target tissue, and limited toxicity of cancer cells $[83,84]$. Therefore, in general it can be said that although bacteria can be used as anti-tumor agents, however, it has major limitations including bacterial toxicity, DNA instability and limited targeting efficiency, lack of selection of appropriate, safe bacterial strain and lack of accompaniment with other therapeutic approaches $[85,86]$.

\section{Conclusion}

Death and relapse rates and higher occurrence of a different kind of cancer reveal us that conventional cancer therapies are not effective enough and cause numerous side effects on the cancer patients. Therefore, nowadays researchers are concentrating on other approaches such as bacteriotherapy as a novel effective therapeutic method with fewer or with no side effects to pay the way of cancer therapy [87]. Several applications of bacterial agent have been developed by taking into consideration of their special features for tumor targeting such as post-administration control, specific internalization into the cancer cells, having specific toxicity against cancer cells, great cytotoxic activity, easy design and modification $[87,88]$. Despite these special features of bacteria using for bacteriotherapy the drawbacks of this method cannot be overlooked; including the short life of bacterial peptide, innate bacterial toxicity, and unstable DNA [89]. It seems that L. monocytogenes strain induced an effective anti-tumor T-cell response,

Table 4 Bacteria as carriers for colorectal cancer therapeutic agents

\begin{tabular}{llll}
\hline Microorganism & Gram Information & Combined agent & References \\
\hline Lysteria monocytogenes & Gram-positive & Anti-cancer vaccines & [68] \\
Salmonella typhimurium & Gram-negative & Cytokines like IL-2, CCL21, Cytotoxic proteins, enzymes, vaccines & [71, 74-76] \\
E.coli Nissle 1917 & Gram negative & P53 and Tum-5 protein & [64] \\
Clostridium novyi-NT & Gram-positive & Liposomal doxorubicin & [73] \\
\hline
\end{tabular}




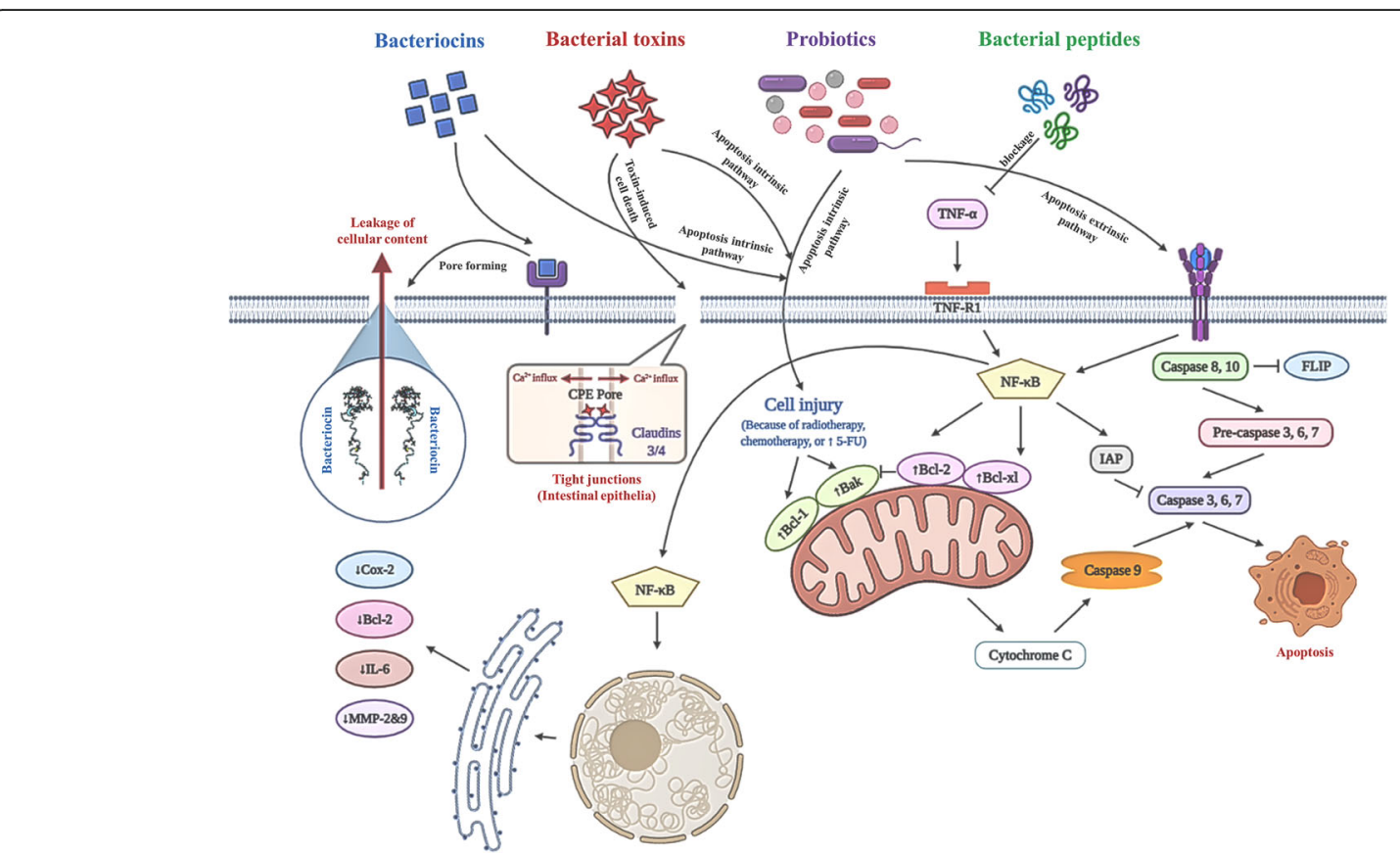

Fig. 3 Some of the underlying molecular mechanisms for colorectal cancer bacteriotherapy. The whole cell bacteria (especially Lactic acid bacteria known as LABs) may lead cancer cells to apoptosis through intrinsic or extrinsic pathways. Bacterial peptides such as arenamides can prevent TNF-induced expression of pro-inflammatory mediators by NF-KB pathway blockage. Bacterial toxins such as C. perfringens enterotoxin (CPE) can directly interact with claudin-3 and claudin-4, which are over-expressed in colorectal cancerous cell membrane. This attachment results in pore formation through the membrane and cell death due to loss of cellular osmotic equilibrium. Another mechanism for bacterial toxins' anticancer effect is cytotoxicity through apoptosis intrinsic pathway. Bacteriocins such as nisin are able to form membrane-pores when they bind to special type of cell surface receptors which cause leakage of cellular content and cell death. Besides pore formation activity, bacteriocins may act as apoptosis initiator through the intrinsic pathway $[10,16,30,50,65,68,69]$

therefore provide it can be used in vaccine development for CRC patients with liver metastasis [90]. In addition, S. typhimurium declined the tumor size and improves the survival in a mouse model of CRC via increasing the hepatic NK cells [91].

$\mathrm{n}$ regard to pons and cons of this approach, most research on bacteriotherapy have been ending in the in vitro phase and only a few ones have gone from the in vitro condition to the clinical trial due to possible uncontrolled complications and side effects which mean that there is still room for exploring further [92, 93]. Since, CRC is a multifactorial disease, a single treatment cannot destroy the tumor and a combination of new and diverse treatments is necessary. By the way, bacterial therapy is combined with traditional methods, has been effectively used to treat CRC patients with positive results. Bacterial therapy of CRC using peptides and toxins is a talented method to save the lives of numerous CRC patients. Nonetheless, further surveys are necessary to improve the effectiveness of this novel strategy to use it in medical practice without any more harmful effects on patients' health.

\section{Abbreviations}

CRC: Colorectal cancer; IBD: Inflammatory bowel disease; 5-FU: 5-Fluorouracil; CDTs: Cytolethal distending toxins; Cif: Cycle inhibiting factor;
CEA: Carcinoembryonic antigen; CNF: Cytotoxic necrotizing factor; DT: Diphtheria toxin; $T_{\text {reg: }}$ Regulatory T cells; STm: Salmonella enterica serovar Typhimurium; STm ${ }^{\Delta a r o}$ : Aromatase A-deficient STm; TNF-a: Tumor necrosis factor a; Entap: Enterococcal anti-proliferative peptide; NRPs: Nonribosomal Peptides; NRPSs: Non-ribosomal peptide synthetases; TLR: Toll-Like receptors; PAMPs: Pathogen-associated molecular patterns; 4-1BBL: Vector for 4-1BB ligand; FMT: Fecal matter transplantation; IMT: Intestinal microbiota transplantation

\section{Acknowledgments}

The authors acknowledge Molecular Medicine Research Center, Bio-medicine Institute, Tabriz University of Medical Sciences.

\section{Authors' contributions}

The core idea of this study came from SE1, HA, AS and VT. They also directed the other authors and analyzed the collected papers. HA, VE, KH, and AS, wrote the manuscript in collaboration with TG and SRS. Final editing was done by SE2 and VT. All authors have read and approved the manuscript.

\section{Funding}

This work was supported by Tabriz University of Medical Sciences of Iran [Grant number 66901]. The funders had no role in study design, data collection and analysis, decision to publish, or preparation of the manuscript.

\section{Availability of data and materials}

The datasets used and/or analyzed during the current study are available from the corresponding author on reasonable request. 


\section{Declarations}

Ethics approval and consent to participate

Not applicable.

\section{Consent for publication}

Not applicable.

\section{Competing interests}

The authors declare that they have no competing interests.

\section{Author details}

'Department of Pharmaceutical Biotechnology, Faculty of Pharmacy, Tabriz University of Medical Sciences, Tabriz, Iran. ${ }^{2}$ Department of Food Science and Technology, Faculty of Nutrition and Food Science, Tabriz University of Medical Sciences, Tabriz, Iran. ${ }^{3}$ Department of Biology, Faculty of Natural Sciences, University of Tabriz, Tabriz, Iran. ${ }^{4}$ Molecular Medicine Research Center, Biomedicine Institute, Tabriz University of Medical Sciences, Tabriz, Iran. ${ }^{5}$ Department of Pharmaceutical Biotechnology, School of Pharmacy, Shahid Beheshti University of Medical Sciences, Tehran, Iran. ${ }^{6} \mathrm{Clinical}$ Research Development Unit of Sina Educational, Research and Treatment Center, Tabriz University of Medical Sciences, Tabriz, Iran. ${ }^{7}$ Department of Biology, Tabriz Branch, Islamic Azad University, Tabriz, Iran. ${ }^{8}$ Biotechnology Research Center, Tabriz Branch, Islamic Azad University, Tabriz, Iran.

\section{Received: 14 April 2021 Accepted: 1 July 2021}

\section{Published online: 19 July 2021}

\section{References}

1. Bray F, Ferlay J, Soerjomataram I, Siegel RL, Torre LA, Jemal A. Global cancer statistics 2018: GLOBOCAN estimates of incidence and mortality worldwide for 36 cancers in 185 countries. CA Cancer J Clin. 2018;68(6):394-424. https://doi.org/10.3322/caac.21492.

2. Macrae FA. Colorectal cancer: Epidemiology, risk factors, and protective factors. Uptodate com [ažurirano 9 lipnja 2017]; 2016.

3. Ebrahimi V, Soleimanian A, Ebrahimi T, Azargun R, Yazdani P, Eyvazi S, et al. Epigenetic modifications in gastric cancer: focus on DNA methylation. Gene. 2020;742:144577. https://doi.org/10.1016/j.gene.2020.144577.

4. Aleksandra M, Urbanska XZ. Satya Prakash. Orally Delivered AntiInflammatory Agents: Bioengineered Colorectal Cancer Drugs; 2015.

5. Rehman AU, Hashmi MA, Tehseen Y, Khan A, Khan SS, lqbal J, et al. Antidiabetic flavonol glycosides from Eryngium caeruleum. Rec Nat Prod. 2017;11(2):229-34

6. Eyvazi S, Vostakolaei MA, Dilmaghani A, Borumandi O, Hejazi MS, Kahroba H, et al. The oncogenic roles of bacterial infections in development of cancer. Microb Pathog. 2020;141:104019. https://doi.org/10.1016/j.micpath.2020.104019.

7. Kostic AD, Chun E, Robertson L, Glickman JN, Gallini CA, Michaud M, Clancy TE, Chung DC, Lochhead P, Hold GL, El-Omar EM. Fusobacterium nucleatum potentiates intestinal tumorigenesis and modulates the tumor-immune microenvironment. Cell Host Microbe. 2013;14(2):207-15.

8. K. R. Fusobacterium nucleatum found in colon cancer tissue--could an infection cause colorectal cancer? 2011.

9. Beheshtirouy S, Eyvazi S, Tarhriz V. Evaluation of Mutations in 235 rRNA, rdxA and frxA Genes of Helicobacter pylori in Paraffin-Embedded GastricBiopsy Specimens from Iranian Gastric Cancer and Gastritis Patients. J Gastrointest Cancer. 2021;52(1):207-11.

10. Song S, Vuai MS, Zhong M. The role of bacteria in cancer therapy-enemies in the past, but allies at present. Infec Agents Cancer. 2018;13(1):9. https:// doi.org/10.1186/s13027-018-0180-y.

11. Ernst J, Kuipers WMG, Lieberman D, Seufferlein T, Sung JJ, Boelens PG, et al. Colorectal cancer; 2015.

12. Seyfi R, Kahaki FA, Ebrahimi T, Montazersaheb S, Eyvazi S, Babaeipour V, et al. Antimicrobial peptides (AMPs): roles, functions and mechanism of action. Int J Pept Res Ther. 2020;26(3):1451-63. https://doi.org/10.1007/s1 0989-019-09946-9.

13. Elyasifar B, Jafari S, Hallaj-Nezhadi S, Chapeland-leclerc F, Ruprich-Robert G, Dilmaghani A. Isolation and identification of antibiotic-producing halophilic bacteria from dagh biarjmand and haj aligholi salt deserts, Iran. Pharmaceutical Sci. 2019;25(1):70-7. https://doi.org/10.15171/PS.2019.11.

14. Tarhriz V, Eyvazi S, Shakeri E, Hejazi MS, Dilmaghani A. Antibacterial and antifungal activity of novel freshwater bacterium Tabrizicola aquatica as a prominent natural antibiotic available in Qurugol Lake. Pharmaceutical Sci. 2020;26(1):88-92. https://doi.org/10.34172/PS.2019.56.

15. Kucerova P, Cervinkova M. Spontaneous regression of tumour and the role of microbial infection-possibilities for cancer treatment. Anti-Cancer Drugs. 2016;27(4):269-77. https://doi.org/10.1097/CAD.0000000000000337.

16. Kramer MG, Masner M, Ferreira FA, Hoffman RM. Bacterial therapy of cancer: promises, limitations, and insights for future directions. Front Microbiol. 2018;9:16. https://doi.org/10.3389/fmicb.2018.00016.

17. Murphy C, Rettedal E, Lehouritis P, Devoy C, Tangney M. Intratumoural production of TNFa by bacteria mediates cancer therapy. PloS one. 2017; 12(6):e0180034.

18. Felgner S, Kocijancic D, Frahm M, Heise U, Rohde M, Zimmermann $K$, et al. Engineered Salmonella enterica serovar typhimurium overcomes limitations of anti-bacterial immunity in bacteria-mediated tumor therapy. Oncoimmunology. 2018;7(2):e1382791. https://doi.org/10.1080/2162402X.2017.1382791.

19. Yang J, Wu Z, Chen Y, Hu C, Li D, Liao Y, et al. A novel radio-sensitization method for lung cancer therapy: enhanced radiosensitization induced by antigens/antibodies reaction after targeting tumor hypoxia using Bifidobacterium. 2020

20. Zhou S, Gravekamp C, Bermudes D, Liu K. Tumour-targeting bacteria engineered to fight cancer. Nat Rev Cancer. 2018;18(12):727-43. https://doi. org/10.1038/s41568-018-0070-z.

21. El-Naggar NE-A, Deraz SF, Soliman HM, El-Deeb NM, El-Ewasy SM. Purification, characterization, cytotoxicity and anticancer activities of $\mathrm{L}$ asparaginase, anti-colon cancer protein, from the newly isolated alkaliphilic Streptomyces fradiae NEAE-82. Sci Rep. 2016;6(1):32926. https://doi.org/10.1 038/srep32926.

22. Baindara P, Gautam A, Raghava G, Korpole S. Anticancer properties of a defensin like class IId bacteriocin Laterosporulin10. Sci Rep. 2017;7(1):46541. https://doi.org/10.1038/srep46541.

23. Geng W, Yang C, Gu Y, Liu R, Guo W, Wang X, et al. Cloning of $\varepsilon$-poly-Llysine $(\varepsilon-P L)$ synthetase gene from a newly isolated $\varepsilon$-PL-producing $S$ treptomyces albulus NK 660 and its heterologous expression in S treptomyces lividans. Microb Biotechnol. 2014;7(2):155-64. https://doi.org/1 $0.1111 / 1751-7915.12108$

24. Husain I, Sharma A, Kumar S, Malik F. Purification and characterization of glutaminase free asparaginase from Enterobacter cloacae: in-vitro evaluation of cytotoxic potential against human myeloid leukemia HL-60 cells. PLoS One. 2016;11(2):e0148877.

25. Karpiński TM, Adamczak A. Anticancer activity of bacterial proteins and peptides. Pharmaceutics. 2018;10(2):54. https://doi.org/10.3390/pharma ceutics 10020054.

26. Sharma A, Bala K, Husain I. Preliminary evaluation of arginine deiminase activity of indigenous bacterial strains for suitable chemotherapeutic applications. Biocatalysis Agricultural Biotechnol. 2017;12:66-77. https://doi. org/10.1016/j.bcab.2017.09.001

27. Su C, Xiang Z, Liu Y, Zhao X, Sun Y, Li Z, et al. Analysis of the genomic sequences and metabolites of Serratia surfactantfaciens sp. nov. YD25 T that simultaneously produces prodigiosin and serrawettin W2. BMC Genomics. 2016;17(1):865.

28. Roberts NJ, Zhang L, Janku F, Collins A, Bai R-Y, Staedtke V, et al. Intratumoral injection of Clostridium novyi-NT spores induces antitumor responses. Sci Transl Med. 2014;6(249):249ra111.

29. RHaY Z. Probiotics in the Treatment of Colorectal Cancer; 2018.

30. Karpiński T.M. SAKICB, Finglas P.M., Toldra F., editors. Encyclopedia of Food and Health. Bacteriocins. 2016.

31. Kaur S, Kaur S. Bacteriocins as potential anticancer agents. Front Pharmacol. 2015;6:272.

32. Varas MA, Muñoz-Montecinos C, Kallens V, Simon V, Allende ML, Marcoleta $A E$, et al. Exploiting zebrafish xenografts for testing the in vivo Antitumorigenic activity of Microcin E492 against human colorectal Cancer cells. Front Microbiol. 2020;11:405. https://doi.org/10.3389/fmicb.2020.00405.

33. Ahmadi S, Ghollasi M, Hosseini HM. The apoptotic impact of nisin as a potent bacteriocin on the colon cancer cells. Microb Pathog. 2017;111:1937. https://doi.org/10.1016/j.micpath.2017.08.037.

34. Norouzi Z, Salimi A, Halabian R, Fahimi H. Nisin, a potent bacteriocin and anti-bacterial peptide, attenuates expression of metastatic genes in colorectal cancer cell lines. Microb Pathog. 2018;123:183-9. https://doi.org/1 0.1016/j.micpath.2018.07.006

35. Lewies A, Du Plessis LH, Wentzel JF. The cytotoxic, antimicrobial and anticancer properties of the antimicrobial peptide Nisin $Z$ alone and in 
combination with conventional treatments. Cytotoxicity. 2018;21. https://doi. org/10.5772/intechopen.71927.

36. Kohoutova D, Forstlova M, Moravkova P, Cyrany J, Bosak J, Smajs D, et al. Bacteriocin production by mucosal bacteria in current and previous colorectal neoplasia. BMC Cancer. 2020;20(1):1-7.

37. Chumchalova J, Šmarda J. Human tumor cells are selectively inhibited by colicins. Folia Microbiol. 2003;48(1):111-5. https://doi.org/10.1007/BF02931286.

38. WW LLE, Rodnina MV. Colicins and their potential in cancer treatment; 2007.

39. Baindara P, Korpole S, Grover V. Bacteriocins: perspective for the development of novel anticancer drugs. Appl Microbiol Biotechnol. 2018; 102(24):10393-408. https://doi.org/10.1007/s00253-018-9420-8.

40. Villarante KI, Elegado FB, Iwatani S, Zendo T, Sonomoto K, de Guzman EE. Purification, characterization and in vitro cytotoxicity of the bacteriocin from Pediococcus acidilactici K2a2-3 against human colon adenocarcinoma (HT29) and human cervical carcinoma (HeLa) cells. World J Microbiol Biotechnol. 2011;27(4):975-80. https://doi.org/10.1007/s11274-010-0541-1.

41. Macarena A, Varas CM-M, Kallens V, Simon V, Allende ML, Marcoleta AE, et al. Exploiting Zebrafish Xenografts for Testing the in vivo Antitumorigenic Activity of Microcin E492 Against Human Colorectal Cancer Cells; 2020.

42. Masso-Welch P, Girald Berlingeri S, King-Lyons ND, Mandell L, Hu J, Greene CJ, et al. LT-IIc, a bacterial type II heat-labile enterotoxin, induces specific lethality in triple negative breast cancer cells by modulation of autophagy and induction of apoptosis and necroptosis. Int J Mol Sci. 2019;20(1):85.

43. Nougayrède J-P, Taieb F, De Rycke J, Oswald E. Cyclomodulins: bacterial effectors that modulate the eukaryotic cell cycle. Trends Microbiol. 2005; 13(3):103-10. https://doi.org/10.1016/j.tim.2005.01.002.

44. Shafiee F, Aucoin MG, Jahanian NA. Targeted diphtheria toxin based therapy: a review article. Front Microbiol. 2019;10:2340. https://doi.org/10.33 89/fmicb.2019.02340

45. Weerakkody $L R$, Witharana $C$. The role of bacterial toxins and spores in cancer therapy. Life Sci. 2019;235:116839.

46. Pahle J, Menzel L, Niesler N, Kobelt D, Aumann J, Rivera M, et al. Rapid eradication of colon carcinoma by Clostridium perfringens enterotoxin suicidal gene therapy. BMC Cancer. 2017;17(1):129. https://doi.org/10.1186/ s12885-017-3123-x.

47. Sasaki T, Mori S, Kishi S, Fujiwara-Tani R, Ohmori H, Nishiguchi Y, et al. Effect of proton pump inhibitors on colorectal Cancer. Int J Mol Sci. 2020;21(11): 3877. https://doi.org/10.3390/ijms21113877.

48. Szeponik L, Akeus P, Rodin W, Raghavan S, Quiding-Järbrink M. Regulatory T cells specifically suppress conventional CD8aß T cells in intestinaltumors of APCMin/+ mice. Cancer Immunol Immunother. 2020;69(7):1279.

49. Maslowski KM, Takahashi M, Nakanishi Y, Mackie GM, Everard I, Copland A, Oda H, Kanaya T, Ohno H. Attenuated Salmonella typhimurium cancer therapy has direct effects on the tumor epithelium in colorectal cancer. Biorxiv. 2019:741686.

50. Patyar S, Joshi R, Byrav DP, Prakash A, Medhi B, Das B. Bacteria in cancer therapy: a novel experimental strategy. J Biomed Sci. 2010;17(1):21. https:// doi.org/10.1186/1423-0127-17-21.

51. Yaghoubi A, Khazaei M, Hasanian SM, Avan A, C Cho W, Soleimanpour S. Bacteriotherapy in Breast Cancer. Int J Mol Sci. 2019;20(23):5880.

52. Arora PK. Microbial Technology for the Welfare of society: springer; 2019 https://doi.org/10.1007/978-981-13-8844-6.

53. Cho JY, Williams PG, Kwon HC, Jensen PR, Fenical W. Lucentamycins a- D, cytotoxic peptides from the marine-derived actinomycete Nocardiopsis lucentensis. J Nat Prod. 2007;70(8):1321-8. https://doi.org/10.1021/np070101 b.

54. Asolkar RN, Freel KC, Jensen PR, Fenical W, Kondratyuk TP, Park E-J, et al. Arenamides a- C, cytotoxic NFKB inhibitors from the marine actinomycete Salinispora arenicola. J Nat Prod. 2009;72(3):396-402. https://doi.org/10.1 021/np800617a.

55. Krupa A, Descamps M, Willart J-F, Strach B, Eb W, Jachowicz R, et al. Highenergy ball milling as green process to vitrify tadalafil and improve bioavailability. Mol Pharm. 2016;13(11):3891-902. https://doi.org/10.1021/acs. molpharmaceut.6b00688.

56. Zhang HL, Hua HM, Pei YH, Yao XS. Three new cytotoxic cyclic acylpeptides from marine Bacillus sp. Chem Pharm Bull. 2004;52(8):1029-30. https://doi. org/10.1248/cpb.52.1029.

57. Matsuo Y, Kanoh K, Yamori T, Kasai H, Katsuta A, Adachi K, et al. Urukthapelstatin a, a novel cytotoxic substance from marine-derived Mechercharimyces asporophorigenens YM11-542. J Antibiotics. 2007;60(4): 251-5. https://doi.org/10.1038/ja.2007.30.
58. Huang F, Qianhui S, Zhaojie Q, Jianglin T, Zhengding S, Yongqi H, Gao M. Anticancer actions of azurin and its derived peptide p28. Protein J. 2020; 39(2):182-9.

59. Goto M, Yamada T, Kimbara K, Horner J, Newcomb M, Gupta TD, et al. Induction of apoptosis in macrophages by Pseudomonas aeruginosa azurin: tumour-suppressor protein p53 and reactive oxygen species, but not redox activity, as critical elements in cytotoxicity. Mol Microbiol. 2003;47(2):549-59. https://doi.org/10.1046/j.1365-2958.2003.03317.x.

60. Cho J-H, Lee M-H, Cho Y-J, Park B-S, Kim S, Kim G-C. The bacterial protein azurin enhances sensitivity of oral squamous carcinoma cells to anticancer drugs. Yonsei Med J. 2011;52(5):773-8. https://doi.org/10.3349/ymj.2011.52.5.773.

61. Drider D, Bendali F, Naghmouchi K, Chikindas ML. Bacteriocins: not only antibacterial agents. Probiotics Antimicrobial Proteins. 2016;8(4):177-82. https://doi.org/10.1007/s12602-016-9223-0.

62. Niamah AK. Structure, mode of action and application of pediocin natural antimicrobial food preservative: a review. Basrah J Agric Sci. 2018;31(1):5969. https://doi.org/10.37077/25200860.2018.76.

63. Agrawal S, Acharya D, Adholeya A, Barrow CJ, Deshmukh SK. Nonribosomal peptides from marine microbes and their antimicrobial and anticancer potential. Front Pharmacol. 2017;8:828. https:/doi.org/10.3389/fphar.2017.00828.

64. Lian He HY, Tang J, Liu Z, Chen Y, Lu B, He H, et al. Intestinal probiotics E. coli Nissle 1917 as a targeted vehicle for delivery of p53 and Tum-5 to solid tumors for cancer therapy; 2019.

65. Mansour Sedighi AZB, Michael R, Hamblin EO, Asadi A, Halajzadeh M, Lohrasbi V, et al. Therapeutic bacteria to combat cancer; current advances, challenges, and opportunities; 2019.

66. Martel S. "towards MRI-controlled ferromagnetic and MC-1 Magnetotactic bacterial carriers for targeted therapies in Arteriolocapillar networks stimulated by Tumoral angiogenesis," 2006; 2006.

67. Loeffler DI, Schoen CU, Goebel W, Pilgrim S. Comparison of different live vaccine strategies in vivo for delivery of protein antigen or antigenencoding DNA and mRNA by virulence-attenuated listeria monocytogenes. Infect Immun. 2006;74(7):3946-57. https://doi.org/10.1128/IAl.00112-06.

68. SC LDI, Goebel W, Pilgrim S. Comparison of different live vaccine strategies in vivo for delivery of protein antigen or antigen-encoding DNA and mRNA by virulence-attenuated Listeria monocytogenes; 2006.

69. Kiyoshi Yoshimura AJ, Heather E, Allen LS, Laird CY, Chia SR, Dirk G, et al. Pardoll and Richard D. Selective Targeting of Antitumor Immune Responses with Engineered Live-Attenuated Listeria monocytogenes; 2006.

70. J. JHZaJ-JMM. Targeted Cancer therapy using engineered Salmonella typhimurium. 2016.

71. Jiang SN PS, Lee HJ, Zheng JH, Kim HS, Bom HS, et al. Engineering of bacteria for the visualization of targeted delivery of a cytolytic anticancer agent. 2013.

72. Lehouritis P, Stanton M, McCarthy FO, Jeavons M, Tangney M. Activation of multiple chemotherapeutic prodrugs by the natural enzymolome of tumour-localised probiotic bacteria. J Control Release. 2016;222:9-17.

73. Mengesha A DL, Chiu RK, et al. Potential and limitations of bacterialmediated cancer therapy. 2007.

74. Min. JHZaJ-J. Targeted Cancer Therapy Using Engineered Salmonella typhimurium. 2016.

75. Ha XQ YQ, Zhao HB, Hui L, Wang ML, Peng JH, et al. Inhibitory effects of the attenuated Salmonella typhimurium containing the IL-2 gene on hepatic tumors in mice. . 2012.

76. Loeffler M, Le'Negrate G, Krajewska M, Reed JC. Salmonella typhimurium engineered to produce CCL21 inhibit tumor growth. Cancer Immunol Immunother. 2009:58(5):769-75.

77. Vincent J MG, Chalmin F, et al. 5-fluorouracil selectively kills tumorassociated myeloid-derived suppressor cells resulting in enhanced T celldependent antitumor immunity. 2010.

78. Verena Staedtke NJR, Bai R-Y, Zhou S. Clostridium novyi-NT in Cancer Therapy; 2016.

79. Vincent $Y$, Manji A, Gregory-Miller K, Lee C. A review of management of Clostridium difficile infection: primary and recurrence. Antibiotics. 2015;4(4): 411-23. https://doi.org/10.3390/antibiotics4040411.

80. Cammarota G, laniro G, Gasbarrini A. Fecal microbiota transplantation for the treatment of Clostridium difficile infection: a systematic review. J Clin Gastroenterol. 2014;48(8):693-702. https://doi.org/10.1097/MCG. 0000000000000046.

81. Gough $\mathrm{E}$, Shaikh $\mathrm{H}$, Manges AR. Systematic review of intestinal microbiota transplantation (fecal bacteriotherapy) for recurrent Clostridium difficile 
infection. Clin Infect Dis. 2011;53(10):994-1002. https://doi.org/10.1093/cid/ cir632.

82. Hamilton MJ, Weingarden AR, Sadowsky MJ, Khoruts A. Standardized frozen preparation for transplantation of fecal microbiota for Recurrentclostridium difficileinfection. Official J Am Coll Gastroenterol ACG. 2012;107(5):761-7.

83. Wachsberger P, Burd R, Dicker AP. Tumor response to ionizing radiation combined with antiangiogenesis or vascular targeting agents: exploring mechanisms of interaction. Clin Cancer Res. 2003;9(6):1957-71.

84. Forbes NS. Engineering the perfect (bacterial) cancer therapy. Nat Rev Cancer. 2010;10(11):785-94. https://doi.org/10.1038/nrc2934.

85. Van Mellaert L, Barbé S, Anné J. Clostridium spores as anti-tumour agents. Trends Microbiol. 2006;14(4):190-6. https://doi.org/10.1016/j.tim.2006.02.002.

86. Wei MQ, Ellem KA, Dunn P, West MJ, Bai CX, Vogelstein B. Facultative or obligate anaerobic bacteria have the potential for multimodality therapy of solid tumours. Eur J Cancer. 2007;43(3):490-6. https://doi.org/10.1016/j.ejca.2 006.10.005.

87. Laliani G, Sorboni SG, Lari R, Yaghoubi A, Soleimanpour S, Khazaei M, et al. Bacteria and cancer: different sides of the same coin. Life Sci. 2020;246: 117398. https://doi.org/10.1016/j.lfs.2020.117398.

88. Soleimanpour S, Hasanian SM, Avan A, Yaghoubi A, Khazaei M. Bacteriotherapy in gastrointestinal cancer. Life Sci. 2020;254:117754.

89. Ludgate $\mathrm{CM}$. Optimizing cancer treatments to induce an acute immune response: radiation Abscopal effects, PAMPs, and DAMPs. Clin Cancer Res. 2012:18(17):4522-5. https://doi.org/10.1158/1078-0432.CCR-12-1175.

90. Olino K, Wada S, Edil BH, Pan X, Meckel K, Weber W, et al. Tumor-associated antigen expressing listeria monocytogenes induces effective primary and memory T-cell responses against hepatic colorectal cancer metastases. Ann Surg Oncol. 2012;19(3):597-607. https://doi.org/10.1245/s10434-011-2037-0.

91. Feltis BA, Sahar DA, Kim AS, Saltzman DA, Leonard AS, Sielaff TD. Cyclooxygenase-2 inhibition augments the hepatic antitumor effect of oral Salmonella typhimurium in a model of mouse metastatic colon cancer. Dis Colon Rectum. 2002;45(8):1023-8. https://doi.org/10.1007/s10350-004-63 54-2.

92. Yaghoubi A, Khazaei M, Avan A, Hasanian SM, Soleimanpour S. The bacterial instrument as a promising therapy for colon cancer. Int J Color Dis. 2020; 35(4):595-606

93. Duong MT-Q, Qin Y, You S-H, Min J-J. Bacteria-cancer interactions: bacteriabased cancer therapy. Exp Mol Med. 2019;51(12):1-15. https://doi.org/10.103 8/s12276-019-0297-0.

\section{Publisher's Note}

Springer Nature remains neutral with regard to jurisdictional claims in published maps and institutional affiliations.

Ready to submit your research? Choose BMC and benefit from:

- fast, convenient online submission

- thorough peer review by experienced researchers in your field

- rapid publication on acceptance

- support for research data, including large and complex data types

- gold Open Access which fosters wider collaboration and increased citations

- maximum visibility for your research: over $100 \mathrm{M}$ website views per year

At $\mathrm{BMC}$, research is always in progress.

Learn more biomedcentral.com/submissions 